\title{
As transformações nos modos de edição, publicação e avaliação de periódicos científicos: impactos para a gestão dos processos editoriais
}

\author{
Cláudia Valentina Assumpção Galian' \\ ORCID: 0000-0002-1924-8802 \\ Emerson de Pietri ${ }^{1}$ \\ ORCID: 0000-0001-5060-9891 \\ Rosângela Gavioli Prieto ${ }^{1}$ \\ ORCID: 0000-0003-4013-1163
}

A Revista Educação e Pesquisa finaliza o segundo ano de sua experiência com o modelo de publicação contínua, em volume único. É possível ter agora mais subsídios para organizar os trabalhos conforme esse modelo recém-implementado no periódico (PRIETO; PIETRI, 2018). No caso de Educação e Pesquisa, a não restrição por números com quantidade pré-definida de artigos permitiu a ampliação do montante de trabalhos publicados. De uma média de 60 artigos por ano, quando organizada em números, foram publicados 85 manuscritos, no ano de 2018, e, no ano de 2019, 114 artigos, além das quatro entrevistas que têm sido publicadas anualmente.

Dos artigos publicados no ano de 2019, 8\% deles são provenientes de autores da Universidade de São Paulo, de campi e unidades diversos. Com essa porcentagem, responde-se adequadamente às diretrizes de agências de fomento, de bases indexadoras, e às regras de avaliação de periódicos Qualis da Coordenação de Aperfeiçoamento de Pessoal de Nivel Superior (Capes) recentemente definidas. No entanto, o item da avaliação referente aos níveis de endogenia é um motivo de atenção especial para os responsáveis pela gestão editorial de Educação e Pesquisa, dado que é preciso considerar as dimensões da Universidade de São Paulo, que têm efeitos nas demandas internas por publicação na Revista. É importante que os responsáveis pelas políticas de avaliação na Capes observem as especificidades das Instituições que sediam os periódicos e os diferentes modos como essas especificidades atuam sobre seus princípios de funcionamento, particularmente quanto à endogenia.

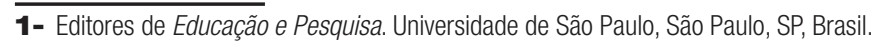


No que se refere à representatividade geográfica dos trabalhos publicados, as preocupações também se mostram presentes quando se observam as distribuições relativas às regiões do país: sul $(14 \%)$ e sudeste $(29,8 \%)$ concentram a maior parcela de publicações realizadas neste ano, enquanto norte (1,7\%), nordeste $(3,5 \%)$ e centro-oeste $(7,8 \%)$ continuam a figurar com menor frequência, mesmo com a intensificação dos esforços de captação de submissões realizas pela Equipe Editorial de Educação e Pesquisa desde o ano de 2018.

0 volume de 2019 reúne 43\% de artigos provenientes de pesquisadores vinculados a instituições estrangeiras. Também atribuída à política editorial de intensificação de publicações em inglês, o volume de 2019 apresenta 59,6\% de seus artigos vertidos para esse idioma. Desse modo, busca-se promover acesso a autores não conhecedores da língua portuguesa aos resultados de pesquisas produzidas no Brasil e em outros países da comunidade lusófona. Na medida da disponibilidade dos autores em verter seus textos, e das condições fınanceiras que tenha o periódico para a realização de suas políticas editoriais, tem-se buscado continuamente ampliar a quantidade de artigos publicados em inglês por Educação e Pesquisa.

0 financiamento do periódico talvez seja a principal preocupação que se apresenta à gestão editorial quando se propõe a publicação contínua sem a restrição a priori da dimensão do volume único a ser produzido. Na experiência de dois anos com a realização deste formato, houve acréscimo de $60 \%$ no número de manuscritos publicados, o que implica mais custos para a edição e a disponibilização dos textos. A responsabilidade para com o desenvolvimento das pesquisas em Educação exige que não se economizem esforços para que parcelas cada vez mais representativas dessas pesquisas sejam levadas a públicos também cada vez mais amplos. É preciso, portanto, que as Instituições sede e as agências de fomento garantam condições para que os periódicos funcionem plenamente em seus objetivos de promover o acesso de qualidade às publicações científicas. No mesmo sentido, é necessário que essas políticas editoriais não sejam orientadas por princípios de avaliação que restrinjam seus objetivos primeiros, reduzindo os periódicos a instrumentos de medição (REGO, 2014; PONCE et al., 2017) e hierarquização de pesquisadores e programas de pós-graduação.

As práticas editoriais têm se reorientado, assim, intensamente em resposta a novos recursos de elaboração, edição e disponibilização de manuscritos. Os modos de busca e acesso a artigos em meio digital, nesse sentido, têm modificado-se, de maneira que a leitura do texto pode se realizar sem que porventura se observe a localização desse texto em conjuntos maiores que os abarquem em unidades materiais: o acesso direto ao artigo via mecanismos de busca digital pode autonomizar o texto, em um processo distinto do que se 
operava com volumes impressos, que conferiam um princípio de unidade à reunião dos textos em seu interior.

Produzem-se, assim, práticas de leitura que rompem com paradigmas historicamente construídos, que relacionam mais estreitamente autor(es), publicação e suporte. ${ }^{2}$ Sem contrapor-se às novas práticas de produção e distribuição de textos, mas tentando dialogar com elas, observando possibilidades diversas de trabalho com a textualidade em meio digital, Educação e Pesquisa tem experimentado a organização de artigos em Seções Temáticas específicas, que possibilitem ao leitor o acesso a conjuntos ordenados de textos em torno de temas específicos. Nesse sentido, coordenada pela Profa. Dra. Rosângela Gavioli Prieto, editora-chefe do periódico de agosto de 2016 a julho de 2019, a Seção Temática Educação Especial reúne artigos que apresentam resultados de pesquisas nos quais se apresentam, ora de modo mais ampliado, ora de modo mais localizado em regiões geográficas específicas, o que tem sido produzido na área no Brasil e em outros países sobre implicações da Politica Nacional de Educação Especial na perspectiva da educação inclusiva desde 2008.

Compõem o volume de 2019 entrevistas com pesquisadores de relevo em seus campos de atuação: esta tem sido uma prática de Educação e Pesquisa que se busca preservar desde sua publicação em formato de números trimestrais e que recebe, no modelo de formato digital, a característica de ser reunida em uma seção específica (e não mais abrindo ou fechando os números publicados).

Por fim, destaca-se também neste editorial que a publicação do volume de 2019 de Educação e Pesquisa se caracteriza por ser uma edição comemorativa dos 50 anos da Faculdade de Educação da USP e dos 60 anos da Escola de Aplicação da Feusp. A Revista Educação e Pesquisa registra, assim, a importância desses marcos temporais e a honra de reconhecer a própria história imbricada no percurso dessas Instituições.

\section{Referências}

CHARTIER, Roger. Os desafios da escrita. Trad. Fulvia M. L. Moretto. São Paulo: Edunesp, 2002.

FOUCAULT, Michel. A Ordem do discurso. São Paulo: Loyola, 1996.

KOMESU, Fabiana; GALLI, Fernanda Correa Silveira. Práticas de leitura e escrita em contexto digital: autoria e(m) novos mídiuns. Revista da Abralin, Curitiba, v. 15, n. 2, p. 165-185, jul. 2016. Disponível em: <https://revistas.ufpr.br/abralin/article/view/47889>. Acesso em: 14 out. 2019.

\footnotetext{
2- Os recursos oferecidos pelos meios digitais de circulação de textos por vezes constroem a ilusão de que o leitor teria assumido uma posição de liberdade plena, irrestrita, em suas práticas de seleção e uso de informações. É preciso observar, no entanto, que as práticas discursivas condicionam as ações dos sujeitos, mesmo quando sob a aparência que os recursos da textualidade eletrônica produzem de não serem orientadas pelos mecanismos tradicionais de controle dos discursos (FOUCAULT, 1996; CHARTIER, 2002; KOMESU; GALLI, 2016).
} 
PONCE, Branca Jurema et al. Sobre a melhoria da produção e da avaliação de periódicos científicos no Brasil. Ensaio, Rio de Janeiro , v. 25, n. 97, p. 1032-1044, dez. 2017. Disponível em: <http://www.scielo. br/scielo.php?script=sci_arttext\&pid=S0104-40362017000401032\&lng=en\&nrm=iso>. Acesso em: 14 out. 2019.

PRIETO, Rosângela Gavioli; PIETRI, Émerson de. Desafios e possibilidades da publicação contínua para 0 trabalho dos editores de periódicos científicos. Educação e Pesquisa, São Paulo, v. 44, e20184401001, 2018. Disponível em: <http://www.scielo.br/scielo.php?script=sci_arttext\&pid=S151797022018000100100\&lng=en\&nrm=iso>. Accesso em: 14 out. 2019.

REGO, Teresa Cristina. Produtivismo, pesquisa e comunicação científica: entre 0 veneno e o remédio. Educação e Pesquisa, São Paulo, v. 40, n. 2, p. 325-346, jun. 2014. Disponível em: <http://www.scielo. br/scielo.php?script=sci_arttext\&pid=S1517-97022014000200003\&lng=pt\&nrm=iso>. Acesso em: 14 out. 2019. 